\title{
Analysis of Shark Skin Riblet Surfaces for Fluid Drag Reduction in Turbulent Flow Regime
}

\author{
A. Sabik Nainar, S. Karthik
}

\begin{abstract}
The integument of fast swimming shark exhibits riblet inspired micro- structured surfaces oriented in the path of flow that will help to make lesser the wall drag in the tempestuous-flow system (turbulent flow). Design have been made for study and utilization, that has been recreate and refine as same as of the shark-skin riblets, presuming an extreme drag depletion of nearly $10 \%$ (percent). Mechanism of fluid drag in tempestuous flow and riblet drag depletion theories from experiments and simulations are examined. An examination of riblet intrepratation are discussed and the stellar riblet sizes are defined. An assessment of studies experimenting with riblets-topped shark scale replicas is also discussed. A method for preferring stellar riblet dimensions based on fluid-flow attributes is briefed and current manufacturing approaches are summarized. Due to the existence of little amounts of mucus/booger membranes on the integument of the shark, it is presumed that the constrained application of aqua phobic materials will recast the flow field around the riblets in some way favorable to the goals of augmented drag depletion
\end{abstract}

Keywords: shark skin; drag depletion; riblets; turbulent flow

\section{INTRODUCTION}

Nature is full of best examples for all the modern scientific technologies and it can be applicable for commercial application. The sharks skin protect against biofouling in the fast movement, acts as armor, and lesser the drag exposed by sharks as they move through the seas. The shark is having microscopic teeth-like scales called dermal denticles (little skin teeth), and ribbed with longitudinal grooves

\section{MECHANISM OF SHARK SKIN}

Researchers innovated ribbed designs on the basis of the fluid-dynamical reasoning by observation of

the structure of shark skins. The fast-swimming sharks skins display riblet structures in the path of flow and it is the reason to reduce the drag in the turbulent-flow regime. The skin of fast moving sharks protect the biofouling, acts as armor, and reduces the drag.
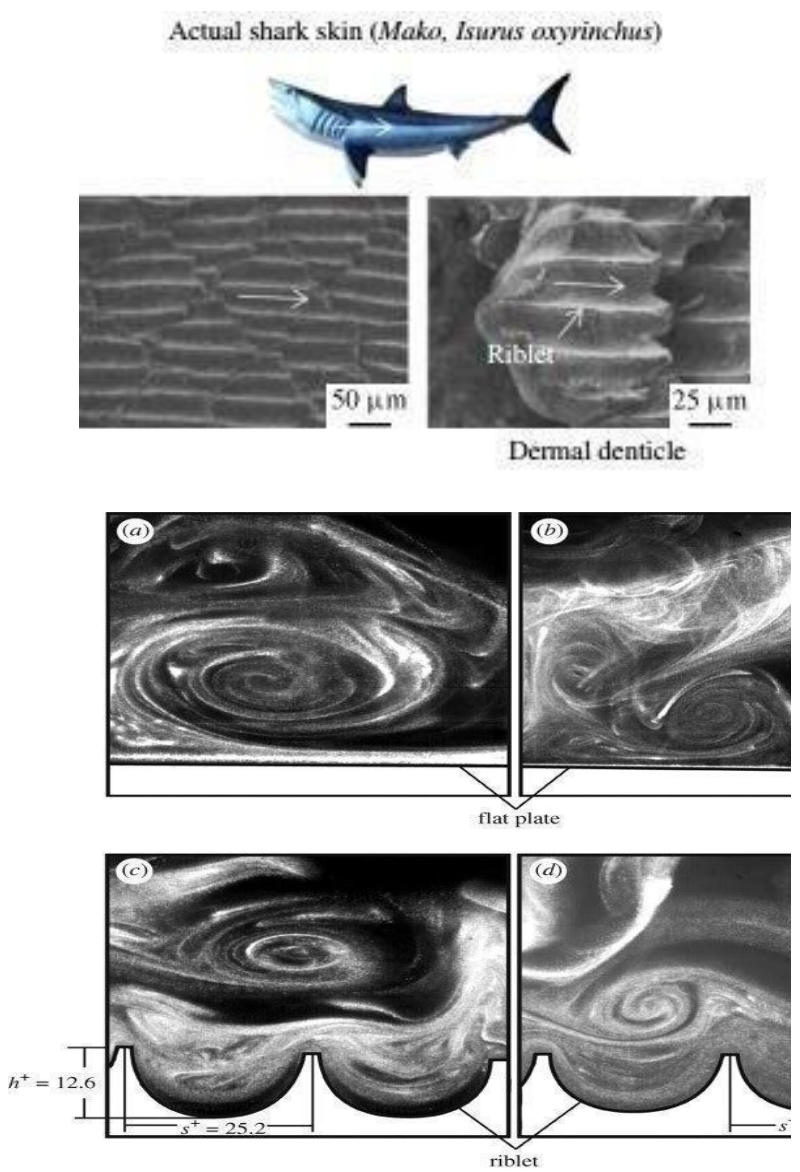

Fig 1: Flow visualization over flat and riblet surfac

\section{METHODOLOGY}

The methodology involves the design methodology and the analysis methodology. The designs are designed by means of computer aided design software CATIA V5. The design is made accurate with modern tool usages. The design of riblet structures are designed on the top surface of the extruded airfoil design. The analysis involves the flow analysis by means of computer aided simulation software ANSYS V15.The flow analysis is done with ANSYS fluent. The results are then plotted by means of graph by the software
Revised Manuscript Received on December 5, 2019

A. Sabik Nainar, Assistant Professor department of Aeronautical

S.Karthik, Assistant Professor, Department of Aeronautical Engineering,

Excel engineering college, Namakkal-637303., India 


\section{DESIGN METHODOLOGY}

The design is done with the computer aided design software CATIA v5. The airfoil coordinates are imported from the internet as previously fed. The design involves the extruded portion of the symmetrical airfoil with the NACA serious of 0012. Then the riblets are designed with the same distinct distances and with the same dimensions.

Different riblet geometries are to be considered for the design purpose. The different geometries are designed with the tools in the CATIA software. The geometries involve V-shaped riblets, U-shaped riblets, Rectangular riblets and silkline geometries. Each of with both continuous and spaced dimensions. The riblets are also designed with the aerodynamic characteristics

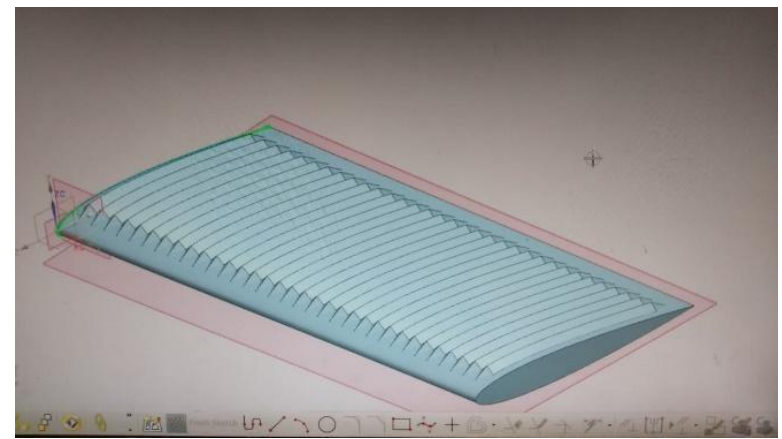

Fig 2.1 (1) V-shaped (continuous)

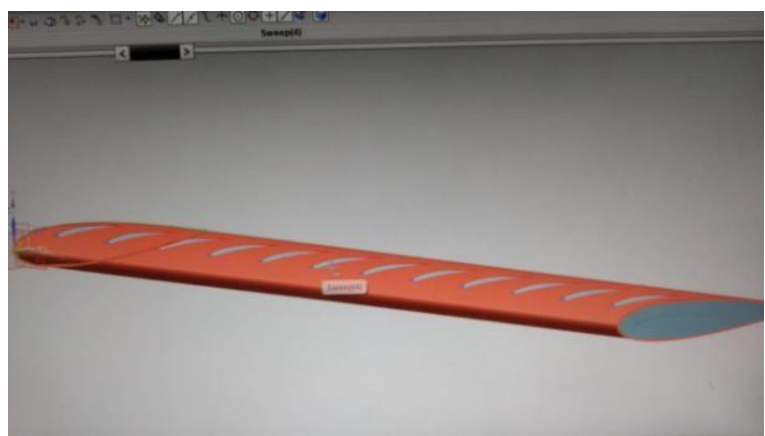

Fig 2.1 (2) Riblets (spaced)

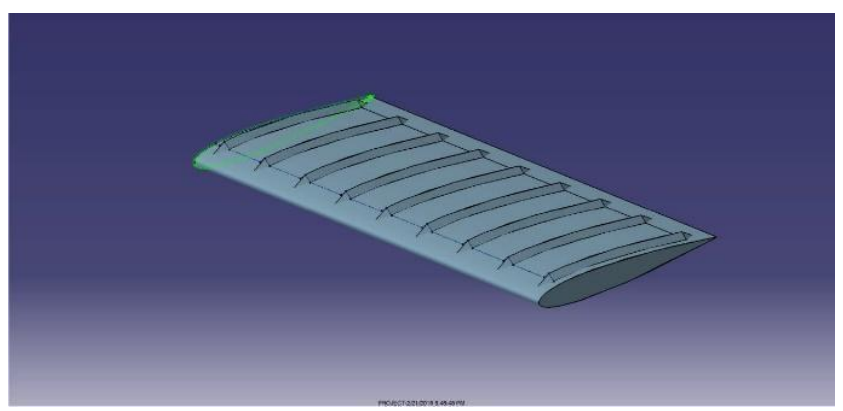

Fig 2.1 (3) V-shaped (spaced)

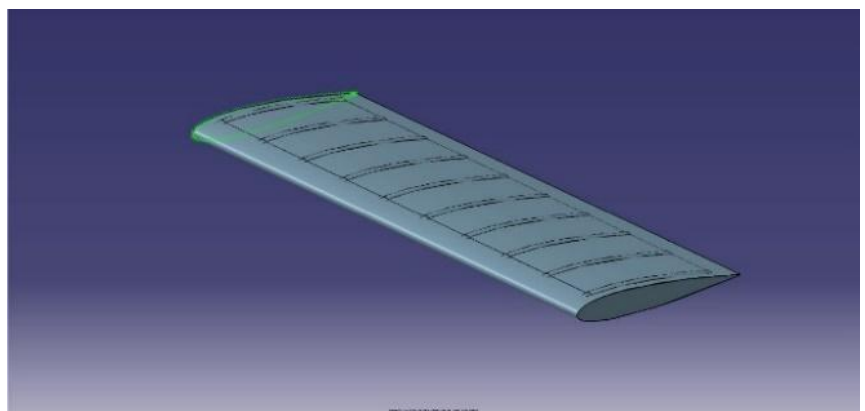

Fig 2.1 (4) U-shaped(spaced)

The design is done with the computer aided simulation software ANSYS 15.ANSYS CFX and FLUENT CFD software are used that provides a perfect modelling fluid flow and other related phenomena.

The design is imported from the designing software CATIA as defined previously. The design is imported which is in the format of step file or in the IGS. The design is meshed for high accuracy flow visualization. More number of iterations are carried for accurate results of flow values.

The design is carried out for the rectangular and extruded airfoil models. The results are taken for the values of lift and drag and in the form of graph. From the flow analysis carried out in the FLUENT CFD, the drag is reduced to some extent when the models are designed with riblets. As a result, when drag reduces the value of lift increases to some extent.

The list of figures that shows the flow results which denotes the value of the coefficient of lift and the coefficient of drag

\subsubsection{FLOW RESULTS FOR RECTANGULAR MODELS}

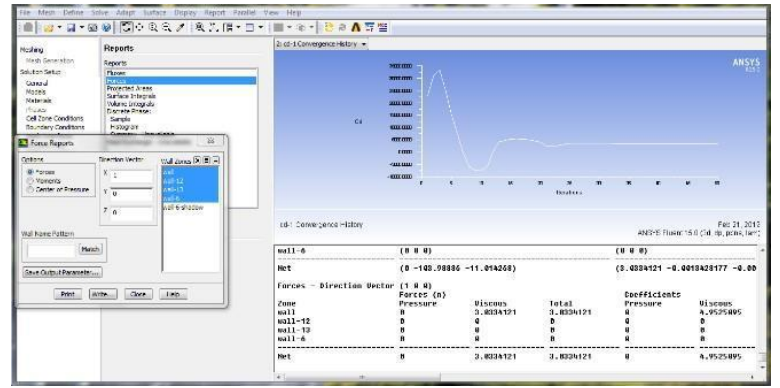

Fig 2.2 (1) Drag results without riblets

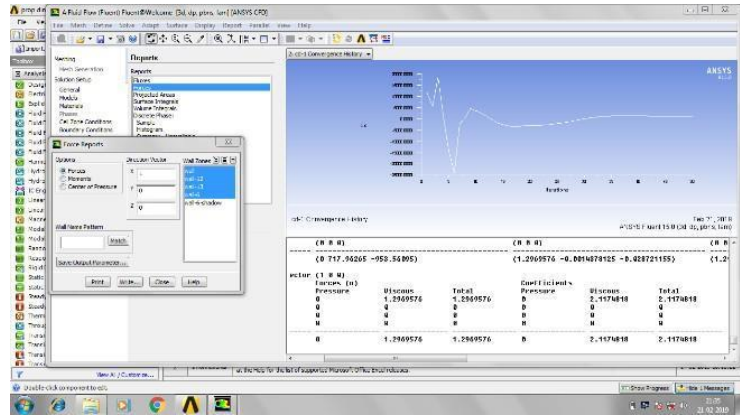

Fig 2.2 (2) Drag results with riblets 


\subsubsection{FLOW RESULTS FOR AIRFOIL MODELS}

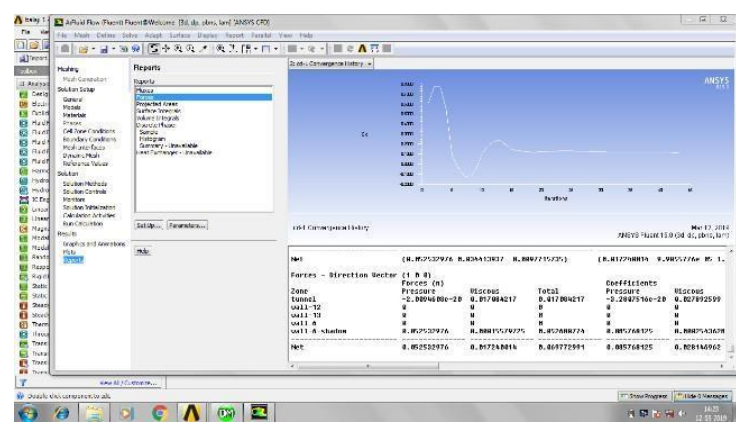

Fig 2.2 (3) Flow results without riblets

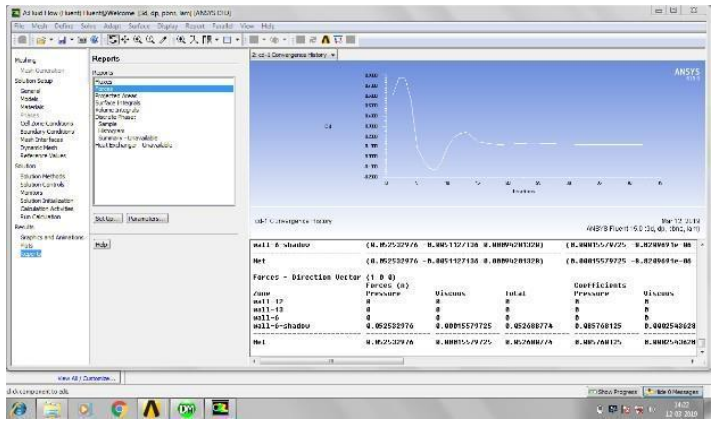

Fig 2.2 (4) flow results with riblets

The flow analysis are carried out for the models for both riblet models and non-riblet models. For rectangular models, the drag is reduced $4.3 \%$ of the existing drag. For airfoil models the drag is reduced to $6.2 \%$ of the existing drag. When if the riblets are designed in micro-scale, the drag will reduce to some more extent.

\section{CONCLUSION}

Animals which are good examples of each and every moving machines. Their skin pattern which can be used for the moving machines to improve their efficiencies. And from those, the sharks have the ability to swim fast in the water and have less fouling because of the micro- structured riblet pattern on their skin. Such riblets effectively reduce the wall drag by lifting and probably attaining naturally obtaining turbulent flow vortices. This reduces the transverse shear stress effects that produced and the momentum change present in the tempestuous flow regime. Lower drag converted to higher fluid flow velocity at the wall surface, so therefore micro-structured impurities are unable to attach and the wall remains clean.

\section{REFERENCES}

1. Walsh, M. J. \& Lindemann, A. M. 1984 Optimization and application of riblets for turbulent drag reduction. AIAA paper 84-0347.

2. Walsh, M. J. 1990 Riblets. In Viscous drag reduction in boundary layers (eds D. M. Bushnell \&J. N. Hefner), pp. 203-261. New York, NY: AIAA.Choi, K.-S. 2000 European drag- reduction research - recent developments and currentstatus.Fluid Dyn. Res. 26, 325-335. (doi:10.1016/S0169-5983(99)00030-1)

3. Bushnell, D. M. 2003 Aircraftdrag reduction-a review. Proc.Inst.Mech. Eng. 17,1-18. (doi:10.1243/095441003763031789)

4. Jiménez, J. 2004 Turbulent flows over rough walls. Annu. Rev. Fluid Mech. 36,173-196.(doi:10.1146/annurev.fluid.36.050802.122103)

5. Bechert, D. W., Bruse, M., Hage, W., der Hoeven, J. G. T. V. \& Hoppe,G. 1997 Experiments on drag-reducing surfaces and their optimization with adjustable geometry. J. Fluid Mech. 338,59-87. (doi:10.1017/S0022112096004673)
6. Bruse, M., Bechert, D. W., der Hoeven, J. G. T. V., Hage, W. \& Hoppe, G. 1993 Experiments with conventional and with novel adjustable drag-reducing surfaces. In Near-wall turbulent flows (eds R. M. C. So, C. G.Speziale \& B.E. Launder), pp. 719-38. Amsterdam, The Netherlands: Elsevier.

7. Bechert, D. W., Bruse, M.,Hage,W. \& Meyer, R. 1997 Biological surfaces and theirtechnological application - laboratory and flight experiments on drag reduction and separation control. AIAA paper 97-1960.

Itoh, M., Tamano, S., Iguchi,R.,Yokota, K., Akino, N., Hino, R. \& Kubo, S. 2006Turbulentdrag reduction by the seal fur surface. Phys. Fluids 18, 065102. (doi:10.1063/1.2204849)

Coustols, E. \& Savill, A. M. 1992 Turbulent skin-friction drag reduction by active andpassivemeans: part I. In Skin friction drag reduction. AGARD report 786, pp. 8.1-8.53. Neuilly-sur-Seine, France: AGARD.

Debisschop, J. R. \& Nieuwstadt ,F.T. M. 1996 Turbulent boundary layer in an adverse pressure gradient: effectiveness of riblets. AIAA J. 34, 932-937. doi:10.2514/3.13170)12 Lee, S.-J. \&Jang, Y.-G. 2005 Control of flow around a NACA 0012 airfoil with a micro-ribletfilm. J. Fluids Struct. 20, 659-672. (doi:10.1016/j.jfluidstructs.2005.03.0 03)

8. Viswanath, P. R. 2002 Aircraft viscous drag reduction using riblets. Prog. Aerosp. Sci.38,571-600. (doi:10.1016/S03760421(02)00048-9)[11]Szodruch, J. 1991 Viscous drag reduction on transport aircraft.AIAA paper91-0685.

9. Robert, J. F. 1992 Drag reduction: an industrial challenge. In Skin friction drag reduction.AGARD report786, pp.2.1-2.15. Neuillysur-Seine, France: AGARD. 16 Roskam, J. 1987 Airplane design. Part VI: preliminary calculation of aerodynamic, thrust and power characteristics. Ottawa, KS: Roskam Aviation and Engineering Corporation

10. Vukoslavcevic, P., Wallace, J.M. \& Balint, J.-L. 1992 Viscous drag reduction using stream wise aligned riblets. AIAA J. 30, 1119-1122.(doi:10.2514/3.11035)

11. Park, S.-R.\& Wallace,J. M. 1994 Flow alterationand drag reduction by riblets in a turbulent boundary layer. AIAA J. 32, 31-38. (doi:10.2514/3.11947)

12. Choi, H., Moin, P. \& Kim, J.1993 Direct numerical simulation of turbulent flow overriblets.J. Fluid Mech. 255, 503-539. (doi:10.1017/S0022112093002575)

13. Chu, D. C. \& Karniadakis, G.E.M. 1993 A direct numerical simulation of laminar and turbulent flow over riblet-mounted surfaces. J. Fluid Mech. 250, 1-42. (doi:10.1017/S0022112093001363)

14. Goldstein, D. B., Handler, R. \& Sirovich, L. 1995 Directnumerical simulation ofturbulentflow over a modeled riblet covered surface. J. Fluid Mech. 302, 333-376. (doi:10.1017/ S0022112095004125)

\section{AUTHORS PROFILE}

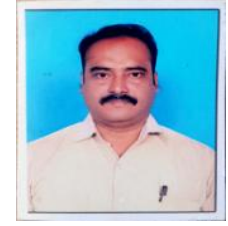

Sabik Nainar, Assistant Professor Aeronautical department Kalasalingham Academic of Research and Education Ex Indian Airforce Life membership In Aeronautical society of India(Graduate) G 11027

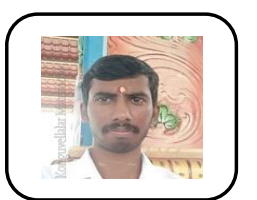

S.Karthik, Assistant Professor, Department of Aeronautical Engineering,

Excel engineering college, Namakkal-637303., India. Email kcg.karthi@gmail.com) 